\title{
Research on the Current Situation of Pension Caregivers in Private Pension Institutions in China
}

\author{
Weifeng $\mathrm{Li}^{\mathrm{a}}$, Huanning Yan ${ }^{\mathrm{b}}$, and Lixia Liang ${ }^{\mathrm{c}, ~}{ }^{\text {* }}$ \\ School of Political Science and Law University of Jinan, Jinan 250022, China. \\ a liweifeng96@163.com, b1170107233@qq.com, c IIxia76@163.com.
}

Keywords: pension caregivers, aging of population.

\begin{abstract}
China's pension pressure is increasing, and pension caregivers are closely related to the life quality of the elderly. Through the form of field observation and interview, problems have been found in the aspects of supply and demand, the sex ratio, the threshold of admittance, the rate of holding, liquidity, working strength and treatment. Their reasons were analyzed by two aspects: industrial structure and ideology. And suggestions are made from three aspects: government, organization and individual.
\end{abstract}

\section{Introduction}

In 2016, there were 1.3 million people aged 60 and above in Jinan, accounting for $20.47 \%$ of its population, far surpassing the provincial average and ranking among the top in the Shandong province. [1] Jinan has entered the moderate aging society and living in a pension institution became the new tendency of the elderly. The elderly care needs to be solved urgently. [2] As the main force in providing services to the elderly, the pension caregivers have played important roles in solving the pension problem. The pension problem has become the focus of national attention, and thus relevant policies have been issued.

\section{Analysis of Current Situation of Pension Caregivers in Private Pension Institutions}

According to the network of pension information, there are 192 pension institutions in Jinan now and 36 in the Shizhong District. [3]I have selected four private pension institutions and observed of their teams.

\subsection{Imbalance and Large Gap Between Supply and Demand.}

According to the data, China needs 13 million pension caregivers urgently, but there were only fewer than one million pension caregivers in our country, and the gap is large. [4] The scholar Kaimei Chen pointed out and confirmed the current situation of imbalance and the large gap between supply and demand of pension caregivers. [5] My observation also confirmed this situation.

The construction plan of social pension service system by the state council pointed out that the ratio of pension caregivers to the elderly is $1: 1$, first-level care is $1: 3$, secondary care is $1: 6$, and tertiary care is 1:10. [6] The total number of elderly people in the four pension institutions is 206. And there should be 69 pension caregivers. But there are only 39 pension caregivers, accounting for $56.5 \%$ compared to the standard requirement. Demand is much greater than supply.

\subsection{The Imbalance Ratio of Male Versus Female and the Dilemma of Heterosexual Nursing.}

A total of 39 pension caregivers in the four institutions, including 6 men, accounting for $15.4 \%$ of the total and 33 women, accounting for $84.7 \%$. Among the elderly in Y pension institution, there are 23 men, accounting for $32.4 \%$, and 48 elderly women, accounting for $67.6 \%$. Among its pension caregivers, there were 3 males, accounting for $21.4 \%$, and 11 females, accounting for $78.6 \%$. There are 16 elderly men people in X pension institution, accounting for $42.1 \%$, and 22 women, accounting for $57.9 \%$. Among the pension caregivers, there are two men, $25 \%$ of the staffs, and six women, accounting for $75 \%$. There are 12 elderly men people in A pension institution, accounting for $36.4 \%$ and 21 women, accounting for $63.6 \%$. Among pension caregivers, there are one man, and are $14.3 \%$ of them. There are 6 women, accounting for $85.7 \%$. There are 21 elderly men people in B pension 
institution, accounting for $32.8 \%$ and 43 women, accounting for $67.2 \%$. Among the pension caregivers, there are two men, accounting for $20 \%$ and 8 women, accounting for $80 \%$. The proportion of men elderly versus women elderly is about 1:3, however in fact the ratio of male and female pension caregivers is about 1:4. This phenomenon leads to an increase in the proportion of heterosexual care in these organizations, thereby contributes to the inconvenience of heterosexual care.

\subsection{Low Barriers of Entrance, High Illegitimate Rate and Low Degree of Specialization.}

Because of the huge demand gap, the pension organizations have no threshold regarding staff recruitment. They did not attach importance in experience and relevant nursing knowledge, and the threshold of entrance for pension caregivers is low, even zero threshold. According to the statistics of 2014, there are less than one million pension caregivers in China, and only about 20,000 of them have professional qualifications. [7] Although the state and Shandong province have relevant policies, which stipulated that the pension caregivers should have the certificate, many institutions have not implemented it. the reason why the pension institution did not pay attention to the qualification certificate is that there is a large gap in the nursing labor force and these organizations were in no position to refuse any potential nursing staffs, especially with consideration in reducing budgets.

Among the four pension institutions, there are 39 pension caregivers, among which 31 are educated only in primary school or below level, accounting for $79.5 \%$, and 8 in middle school education level, accounting for 20.5 percent. They don't have nurse qualification certificates, and the ratio of non-qualification is above $80 \%$ (It does not take into consideration about the phenomenon in only registering certificate not working here). If the pension caregivers come to the institutions, the organization accepts. And they do not need to have relevant knowledge. It has been found in academic studies that other pension institutions showed this phenomenon, indicating large gap in pension caregivers and low threshold, which is more common in Jinan.

\subsection{Excessive Liquidity and High Turnover Rate.}

For continuous observation for the situation of four elderly institution, the pension caregivers number is in circular state of "peak - low - slow rally". Their longest working time are about three months, and most of them left in a month or so. The first reason for the high mobility is the high intensity of work and low payment. The second one is the transitional working nature of this job. If they find a better job, they will waste no time in changing their jobs. Among the four institutions, seven attendants out of them are the transitional ones. The third reason is low social status, low recognition from the public and low public remarks.

\subsection{Strong Work Intensity and Low Pay.}

The average monthly salary of the pension caregivers in Jinan city is 2,800 yuan, about $55.6 \%$ payments are between 2000 and 4000 yuan, and about $29.6 \%$ are receiving 4,000 to 6,000 yuan, and $0 \%$ are receiving more than 6,000 yuan. [8] Among the four pension institutions, Y pension institution has a "performance system", and its monthly salary is between 2,800 and 3,500 yuan. X pension institution and A pension institution implemented the "distribution system according to work", whose payments are basically between 2500 and 3300 yuan according to the number of elderly people. B pension institution implements "basic wage system", and its monthly salary is between 2,800 and 3,400 yuan. They do not pay social security and have poor welfare allowances. According to the statistics of 2016, the average monthly salary of Jinan citizens is 5333 yuan, [9]so the monthly salary of the pension caregivers is far lower than the average salary standard of Jinan citizens. Moreover, most pension caregivers of the four pension institutions do not have social insurance and one housing fund for pension caregivers, which makes most pension caregivers have "temporary" senses of their jobs and lack of professional sense of belonging, except for a few economically developed cities.

All pension caregiver in these four nursing houses have 12 hours of work and only take a break for an hour in the mid-day. They take two days off per month. On average, one person is responsible for the daily care of more than 5 elderly people, whose works including daily life care, organization cleaning and other works. The workload is huge. It is also difficult to attract social workers because of the long working hours, huge workload and low payment and poor welfare allowances. 


\section{Cause Analysis of the Imbalance Between Supply and Demand of Pension Caregivers in Private Pension Institutions}

\subsection{Insufficient Market Development and Lagging Development of Service Industry.}

In 2016, the primary industry, the secondary industry and the tertiary industry have contributed themselves to the GDP of China in proportion of $9.1 \%, 43.1 \%$ and $47.8 \%$ respectively. [10] In some aspects, China's industrial structure was less reasonable, its tertiary industry was developing and well below the level of developed countries.

With its tertiary industry ( $47.3 \%$ ) surpassed its secondary industry for the first time, Shandong province was ranked the seventh in China's service industrial development index by the year of 2016, though it was still lower than the average service level of the country.[11] As an emerging sector of the tertiary industry, the nursing industry is in its rising way, which in turn shows signs of low-leveled and insufficient development.

\subsection{Influence of Ideology.}

The traditional Chinese culture believes that "raise children to support parents when they are old". The family care is the dominant way in the Chinese society, especially in its rural areas. Citizens' acceptance of institutional care was still quite low, which, to a certain extent, led to labor shortage in the elderly care industry. Secondly, the managerial staffs were lagging in knowledge of the elderly care, whom considered that elderly care is physical work, which does not require high professional skills at all. What's more, out of consideration of their budgets, institutional managers tend to select less-educated, unqualified and older (over 40) candidates from rural areas to do the jobs.

The pension caregivers themselves have poor sense of self-identification and efficiency, which seriously affect their working enthusiasm. The low reputation and recognition of the public worsen their attitude towards the work they are engaged in, and even make them have a humiliated feeling.

\section{Suggestions for the Cultivation of Pension Caregivers}

\subsection{Strengthen the Leading Role of the Government.}

Firstly, promote the reconstruction and transformation of the industrial structure and vigorously develop the tertiary industry, especially the development of emerging industries like the elderly care service industry. Secondly, establish a hierarchical and graded cultivation system of elderly nursing care. We should urge the civil administration office to carry out the policy of appraising the vocational skills and organize the pension caregivers to take the appraisal examination. Finally, enhance publicity and improve social recognition. The government should recognize the policy status of the pension caregivers, and then the social status of the pension caregivers should be improved by means of various incentives to improve the industry's reputation in public.

\subsection{Strengthen Institutional Managements.}

Firstly, we shall guide the establishment of the labor market of professional pension service and the recruitment fairs of colleges and universities and help the pension institutions to establish cooperative relations with colleges and universities and establish special channels to strengthen the ranks of pension caregivers by recruiting migrant workers and laid-off workers. Meanwhile, high welfare allowance will attract more people to join in the pension service and retain staff member.

\subsection{Enhance Individual Qualities.}

Firstly, we shall establish a training institution to test people who are trained to be a pension caregiver and must strengthen the re-evaluation of those with qualification, and it should be carried out stably in settled periods. And, the internal ethics of the pension caregivers is the precondition for their job performances. They must understand basic ethics of nursing, such as patience, diligence and fearlessness of being tired. Finally, pension caregivers shall consciously try their best to find out channels to acquire professional knowledge and skills, which will ensure their professional skills and the life quality of those being cared by them. 


\section{Conclusion}

With the rapid aging of the population, China's pension problem is becoming more and more prominent. As the main labor force for providing elderly services, the pension caregivers are closely connected with the quality of life of the elderly. After having visited the four private pension institutions in Jinan city, $i$ has collected information and analyzed the status quo of pension caregivers in private pension institutions. It includes the imbalance between supply and demand, the big gap, the gender imbalance, and large proportion of heterosexual care, low barriers of entrance, high rate of illegitimate recruitment, low degree of specialization, high mobility and turnover rate, great work intensity and low payment. Its reasons were analyzed by two aspects: low market development and outdated thinking. According to the research results, i makes corresponding suggestions.

\section{References}

[1]. Information on: http://news.163.com/17/1024/14/D1H3U0UN00014AED.html

[2]. Xueyuan Tian.The China Geriatric Population. [M].Beijing:Social Sciences Academic Press,2012,p.312.

[3]. Information on: http://www.yanglaocn.com/

[4]. Information on: http://wemedia.ifeng.com/22903281/wemedia.shtml

[5]. Kaiei Chen.The Present Situation of Supply and Demand of Pension Caregivers in Guangdong Province and its Countermeasures. [J]. Economist magazine.Vol.10(2012), p.198-199.

[6]. The State Council.Notice on the Construction Plan of the Social Pension Service System (2011-2015).2011,12.

[7]. Information on:http://mp.weixin.qq.com/s

[8]. Information on: http://www.baixing.com/job/yisheng/m178210/salary_7488/

[9]. Information on: http://news.ifeng.com/a/20170619/51279483_0.shtml

[10]. Information on: http://www.stats.gov.cn/tjsj/

[11]. Information on: http://news.youth.cn/gn/201703/t20170310_9266750.htm 